\title{
Expression of wild type and mutant TSC2, but not TSC1, causes an increase in the $G 1$ fraction of the cell cycle in HEK293 cells
}

\author{
L Khare, A Astrinidis, W Senapedis, P D Adams, E Petri Henske
}

J Med Genet 2002;39:676-680

T uberous sclerosis complex (TSC) is a tumour suppressor gene syndrome whose manifestations include seizures, mental retardation, autism, and tumours of the brain, retina, kidney, heart, and skin. ${ }^{1}$ Mutations in two tumour suppressor genes, TSC1 on chromosome 9q34 and TSC2 on chromosome 16pl3, cause TSC. TSC2 encodes tuberin, a 190 $\mathrm{kDa}$ protein with homology to the catalytic domain of a GTPase activating protein (GAP) for Rapl. ${ }^{2}$ TSCl encodes hamartin, a $130 \mathrm{kDa}$ protein. ${ }^{3}$ Tuberin and hamartin have been shown to directly interact, both in mammalian cells ${ }^{45}$ and in Drosophila.$^{67}$ This is consistent with the nearly identical spectrum of disease seen in humans with TSC1 and TSC2 germline mutations, and with the identical phenotypes of Drosophila $T S C 1^{6-8}$ and TSC2 $2^{9}$ homologue mutants. The mouse models of TSC1 and TSC2 also have similar phenotypes; renal carcinoma and renal cysts develop in heterozygous animals of the Eker rat model of TSC2 $2^{11}$ and in the knock out mouse models of both $T S C 1^{12}$ and TSC $2,{ }^{13}{ }^{14}$ all of which are embryonically lethal in the homozygous form.

The cellular pathways through which germline TSC1 or TSC2 mutations result in tumorigenesis are not completely understood. Mammalian tuberin and hamartin have been shown to suppress cell growth, accompanied by an increase in cells in the Gl phase of the cell cycle. ${ }^{15-17}$ The importance of cell cycle regulation to human TSC is not known. In this study, we used a sensitive fluorescence activated cell sorting approach to investigate the cell cycle effects of wild type hamartin and tuberin, two patient derived mutant forms of tuberin, and a carboxy-terminus construct of tuberin containing the region of GTPase activating protein homology. Similar overexpression approaches using cell sorting have been used to elucidate the cell cycle effects of numerous proteins including the retinoblastoma protein and its family members, PTEN, cyclin dependent kinases, cyclin dependent kinase inhibitors, and substrates of the cyclin dependent kinases. ${ }^{18-26}$

Our goal was to determine the impact of transient expression of wild type tuberin and hamartin, and mutant and truncated forms of tuberin, on the cell cycle. Previously, transient expression of wild type full length tuberin was shown to increase the Gl fraction of cells ${ }^{1617}$ and stable expression of hamartin suppressed cell growth accompanied by an increase in $\mathrm{Gl} .^{15}$

\section{MATERIAL AND METHODS}

We cotransfected cells with TSC1 and/or TSC2 in excess of a construct encoding the cell surface protein CD19, and sorted transfected cells by FACS using an FITC conjugated anti-CD19 antibody. Transfections were performed using calciumphosphate precipitation. The TSC1 and/or TSC2 constructs were transfected in five-fold molar excess of the expression vector encoding the cell surface protein CD19, as previously described. ${ }^{27}$ After transfection, the cells were washed with phosphate buffered saline and cultured in fresh media until trypsinisation at 48 hours post-transfection. A construct encoding the cyclin dependent kinase inhibitor p21(WAF1/ CIP1) was used as a positive control for an increase in the Gl phase of the cell cycle. ${ }^{27}$ A summary of the constructs used in these experiments is shown in fig $1 \mathrm{~A}$. The C-terminus construct has been previously shown to reduce the in vitro proliferation and in vivo tumorigenicity of Eker rat renal carcinoma cells. ${ }^{28}$ Site directed PCR based mutagenesis was performed using the QuickChange Site-Directed Mutagenesis Kit (Stratagene, La Jolla, CA) to generate TSC2 mutants which were then confirmed by DNA sequencing. To generate the exon 16 (G1832A) TSC2 mutant construct, the primers were 5'-GAG CAG CAT CCA GCT GCA GGC C-3' and 5'-GGC CTG CAG CTG GAT GCT GCT C-3'. The G1832A missense change in exon 16 changes the amino acid at position 611 from arginine to glutamine (R611Q). This is a frequent naturally occurring germline mutation in TSC patients ${ }^{29}$ and has recently been found as a somatic mutation in tumour cells from women with the sporadic form of pulmonary lymphangiomyomatosis. ${ }^{30}$ To generate the exon 38 TSC2 mutant (C5024T), the primers were 5'-CAC GTG ATC GTC ACC CTG CTG GAC TAC GAG TGC-3' and 5'-GCA CTC GTA GTC CAG CAG GGT GAC GAT CAC GTG -3'. Constructs were cloned into pcDNA 3.1 + (Invitrogen, Carlsbad, CA). The C5024T missense change in exon 38 changes the amino acid at position 1675, within the GAP related domain, from proline to leucine (P1675L) (fig 1B). This mutation occurs at a highly conserved residue and has been reported in at least 10 unrelated TSC patients (see the TSC Variation Website (http:// expmed.bwh.harvard.edu/ts/) for specific references and further details for both mutations).

Overexpression of the appropriate protein(s) was confirmed by western immunoblot analysis (fig 2A). A polyclonal tuberin C20 antibody (Santa Cruz Biotechnology, Santa Cruz, CA), a polyclonal affinity, purified hamartin antibody developed in our laboratory, ${ }^{5}$ a p27(KIPl) antibody (Oncogene Research Products, San Diego, CA), and an actin antibody (Sigma, St Louis, MO) were used to detect proteins by enhanced chemiluminescence (Amersham, Piscataway, NJ).

\section{Key points}

- To understand the relevance of p27 and cell cycle regulation to the clinical manifestations of TSC, we analysed HEK293 cells overexpressing wild type TSC1, wild type TSC2, or disease causing mutant forms of TSC2.

- Expression of wild type TSC2, but not TSC1, caused an increase in the G1 fraction of the cell cycle. Expression of the TSC2 mutants also resulted in a G1 fraction increase. 
A

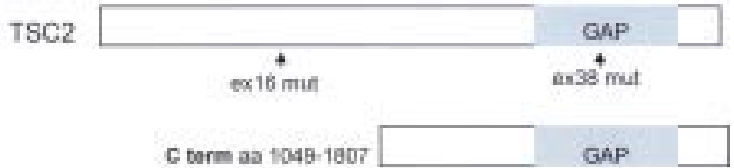

8 Exon 38

Human

Mouse

rugu

Drosophil

Figure 1 (A) TSC2 constructs. Tuberin contains a GTPase activating protein (GAP) related domain near its carboxy terminus. The relative positions of the exon 16 and exon 38 missense mutations and the carboxy-terminus construct (aa 1049-1807) are indicated. This C-terminus construct has been previously shown to reduce the in vitro proliferation and in vivo tumorigenicity of Eker rat renal carcinoma cells. ${ }^{28}$ (B) Evolutionary conservation of TSC2 exon 38. The exon 38 mutant results in a Pro 1675 Leu change $\left({ }^{*}\right)$ within the GAP related domain of tuberin. This mutation has been found in at least 10 unrelated TSC patients. It occurs at a residue that is identical in human, mouse, Fugu, and Drosophila. Residues that are identical in the four species are in red, residues that represent conservation of strong groups are in blue, residues representing conservation of weak groups are in green, and residues that are different are in black.

Two colour fluorescence activated cell sorting (FACS) was used to determine the DNA content of cells transiently transfected with plasmids encoding CD19 and TSC1 or TSC2. ${ }^{27}$ After harvest, the cell pellet was resuspended in $100 \mu \mathrm{l}$ of phosphate buffered saline containing $5 \mu \mathrm{l}$ of FITC conjugated anti-CD19 antibody (Caltag Laboratories, Burlingame, CA), incubated on ice for one hour, and washed twice with PBS containing $0.1 \%$ BSA. The cells were then fixed with $70 \%$ ethanol at $4^{\circ} \mathrm{C}$. Before flow cytometry analysis, the cells were pelleted, washed in phosphate buffered saline, and stained with $20 \mu \mathrm{g} / \mathrm{ml}$ of propidium iodide (Sigma) containing $9.5 \mathrm{mg} / \mathrm{ml}$ RNase (Sigma). Flow cytometry analysis was performed on a BectonDickinson FACScan machine. The intensity of propidium iodide staining was analysed on FITC positive cell populations. The percentages of cells in the G1, S, and G2/M phases of the cell cycle were determined using ModFit cell cycle analysis software version 3.1 (Verity Inc, Topsham, ME). Statistical analysis was performed using a one sided Student's $t$ test. The intensity of PI staining was analysed in the CD19 positive cells and used to determine the percentages of transfected cells in the G1, S, and G2/M phases of the cell cycle.

\section{RESULTS AND DISCUSSION}

We initially analysed U2OS cells, which were derived from a human osteosarcoma. In U2OS cells, the expected increase in Gl was seen with p2l(WAFl/CIPl) transfection, which was used as a positive control, but no change in Gl was found with transfection of TSC1, TSC2, or both (data not shown).

We then studied HEK293 cells, which were derived from human embryonic kidney cells. A small but significant increase in the Gl phase of the cell cycle was observed when wild type TSC2 was overexpressed in HEK293 cells (fig 3). The percentage of cells in Gl was $33.2 \%$ for cells transfected with CD19 and the empty pcDNA vector, compared with $40.6 \%$ for p21(WAF1/CIP1) transfection, $40.9 \%$ for TSC2, and 39.4\% for TSCl plus TSC2. In each case, the increase in the Gl fraction was accompanied by a decrease in the G2 fraction. No significant change in the Gl fraction was found when TSC1 $(30.1 \%$ in G1) or the carboxy-terminus of $\operatorname{TSC} 2(35.2 \%$ in Gl) were overexpressed. This is, to our knowledge, the first time that the

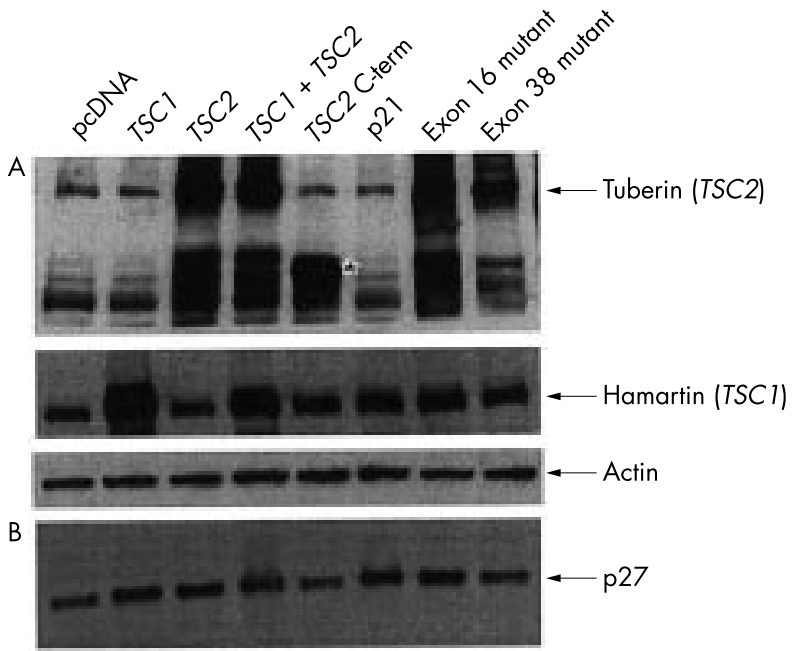

$\begin{array}{llllllll}1.0 & 3.3 & 2.5 & 1.6 & 0.5 & 1.2 & 3.0 & 1.0\end{array}$

Figure 2 Western immunoblot analysis confirming expression of the TSC1 and TSC2 constructs. (A) Overexpression of full length hamartin (migrating at approximately $130 \mathrm{kDa}$ ) is seen in the cells transfected with $T S C 1$ or $T S C 1+T S C 2$, overexpression of full length tuberin (migrating at approximately $190 \mathrm{kDa}$ ) is seen in the cells transfected with TSC2 or TSC1 + TSC2. Overexpression of the carboxy-terminus of TSC2 is seen as a band migrating at the expected size of approximately $80 \mathrm{kDa}$ (indicated with an asterisk), with no change in the expression of full length tuberin in this lane. Overexpression of the exon 16 or exon 38 mutant forms of tuberin results in a band at the same mobility as wild type tuberin, as expected. In each lane with overexpression of wild type or mutant full length tuberin, two additional bands are seen migrating just above and below the carboxy-terminus band. The functional significance of these smaller products is not known. Beta-actin is shown as a loading control. (B) An increase in p27(KIP1) expression was present when TSC1, TSC2, TSC1, and TSC2, or the TSC2 exon 16 mutant were overexpressed, but not when the carboxy-terminus of TSC2 or the TSC2 exon 38 mutant were overexpressed. The number below each lane indicates the relative level of p27 (KIP1) expression (normalised to actin expression) as determined by densitometry. The level of expression in the pcDNA control transfection was arbitrarily set to 1.0 .

cell cycle effects of hamartin have been studied using transient, rather than stable, expression, and the first time that the effects of TSC1 and TSC2 have been directly compared. Our data suggest that tuberin, not hamartin, is responsible for Gl regulation by the hamartin-tuberin complex.

We chose to study HEK293 cells in part because the kidney is a major site of disease in TSC patients. Renal disease in TSC can include angiomyolipomas, cysts, and renal cell carcinomas, ${ }^{31}$ with angiomyolipomas by far the most common renal manifestation. ${ }^{29}$ Renal disease is an important cause of mortality in TSC patients. ${ }^{32}$ The fact that we observed an effect of TSC2 in HEK293 cells but not U2OS cells could reflect intrinsic differences between these cell types, and these differences could be related to the high incidence of renal manifestations among patients with TSC. It is more likely, though, that U2OS cells contain mutations in other genes that block the effect of TSC2. Similar differences between cell lines have been observed for many tumour suppressor genes, including RB. In some cases, the downstream genes that distinguish "sensitive" cells from insensitive cells have been elucidated. ${ }^{22} 23$

The effect of TSC2 on the G1 phase of the cell cycle that we observed in HEK293 cells was substantially enhanced by treating the cells with the anti-microtubule agent nocodazole, which induces a G2/M block. Cells were treated with $70 \mathrm{ng} / \mathrm{ml}$ of nocodazole (Sigma, St Louis, MO) for another 18.5 hours to induce a G2/M phase block. After nocodazole treatment the vector transfected control cells accumulated in G2/M (as 

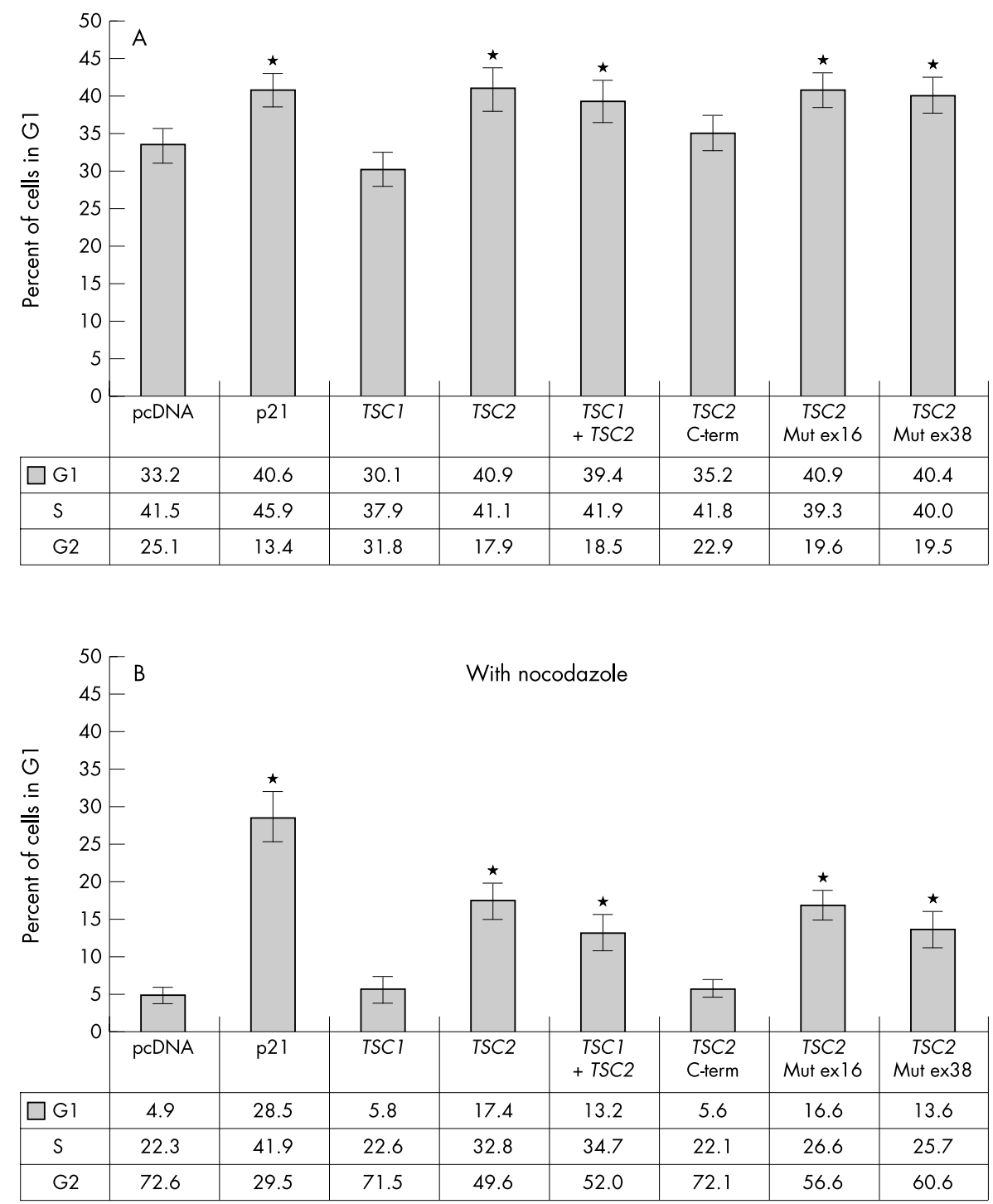

Figure 3 TSC2 expression causes an increase in cells in the G1 phase of the cell cycle. (A) The fraction of cells in the G1, S, and G2 phases of the cell cycle for each transfection is indicated. The percentage of cells in $G 1$ is indicated by the bar height. The standard error of the mean (SEM) is shown in white. An increase in the G1 fraction was seen in cells transfected with p21(WAF1/CIP1), TSC2, TSC1 plus TSC2, the TSC2 exon 16 mutant (TSC2 Mut Ex16), and the TSC2 exon 38 mutant (TSC2 Mut Ex38). There was no change in the G1 fraction for cells transfected with TSC1 or the TSC2 carboxy-terminus (TSC2 C-term). * $\mathrm{p}<0.05$ relative to CD19/pcDNA control. (B) With nocodazole treatment, the majority of the pcDNA/CD19 control transfected cells were in G2/M, as expected. An increase in the G1 fraction was seen in cells transfected with p21(WAF1/CIP1), TSC2, TSC1 plus TSC2, the TSC2 exon 16 mutant (TSC2 Mut Ex16), and the TSC2 exon 38 mutant (TSC2 Mut Ex38). There was no change in the G1 fraction for cells transfected with TSC1 or the TSC2 carboxy-terminus (TSC2 C-term). ${ }^{*} \mathrm{p}<0.05$ relative to the CD19/pcDNA control.

expected) accompanied by a decrease in the Gl population, while the TSC2 transfected cells had a significant accumulation in Gl (figs 3 and 4). The percentage of cells in Gl was $4.9 \%$ for cells transfected with CD19 and the empty pcDNA vector, compared with $28.5 \%$ for p2 1 (WAF1/CIPl) transfection, $17.4 \%$ for wild type TSC2, and $13.2 \%$ for TSC1 plus TSC2 $(\mathrm{p}<0.05$ for each transfection compared with the vector control). In each case the increase in the Gl fraction was accompanied by a decrease in the G2 fraction. No change in any phase of the cell cycle was found when TSC1 (5.8\% in G1) or the carboxy-terminus of TSC2 $(5.6 \%$ in Gl) were overexpressed.

The mechanism through which nocodazole enhances the cell cycle effect of tuberin expression may simply involve cell synchronisation. It is also possible that a protein such as p53 whose activity or level is increased by nocodazole is a key downstream effector of tuberin. We did not observe an increase in p53 levels in nocodazole treated HEK293 cells, but this does not exclude an increase in the transcriptional activity of $\mathrm{p} 53 .{ }^{33}$

We hypothesised that naturally occurring TSC2 missense mutations would not result in the Gl increase seen with wild type TSC2 if perturbation of this pathway is a primary event in disease pathogenesis. Approximately $20 \%$ of germline TSC2 mutations are missense changes. ${ }^{29}{ }^{34}$ For reasons that are not yet understood, all identified TSCl mutations result in premature protein truncation, with no known missense mutations. The functional characterisation of mutant forms of TSC2 is at a very early stage. In our study, expression of two of the most common naturally occurring TSC2 missense mutants, in exons 16 (R61 1Q) and 38 (P1675L), resulted in an increase in the Gl fraction of similar magnitude to that mediated by wild type TSC2. As with wild type TSC2, this effect was enhanced by exposure of the cells to nocodazole (figs 3 and 4). The percentage of cells in Gl with nocodazole treatment was $4.9 \%$ for the pCDNA/CD 19 control, $17.4 \%$ for wild type TSC2, $16.6 \%$ for the 

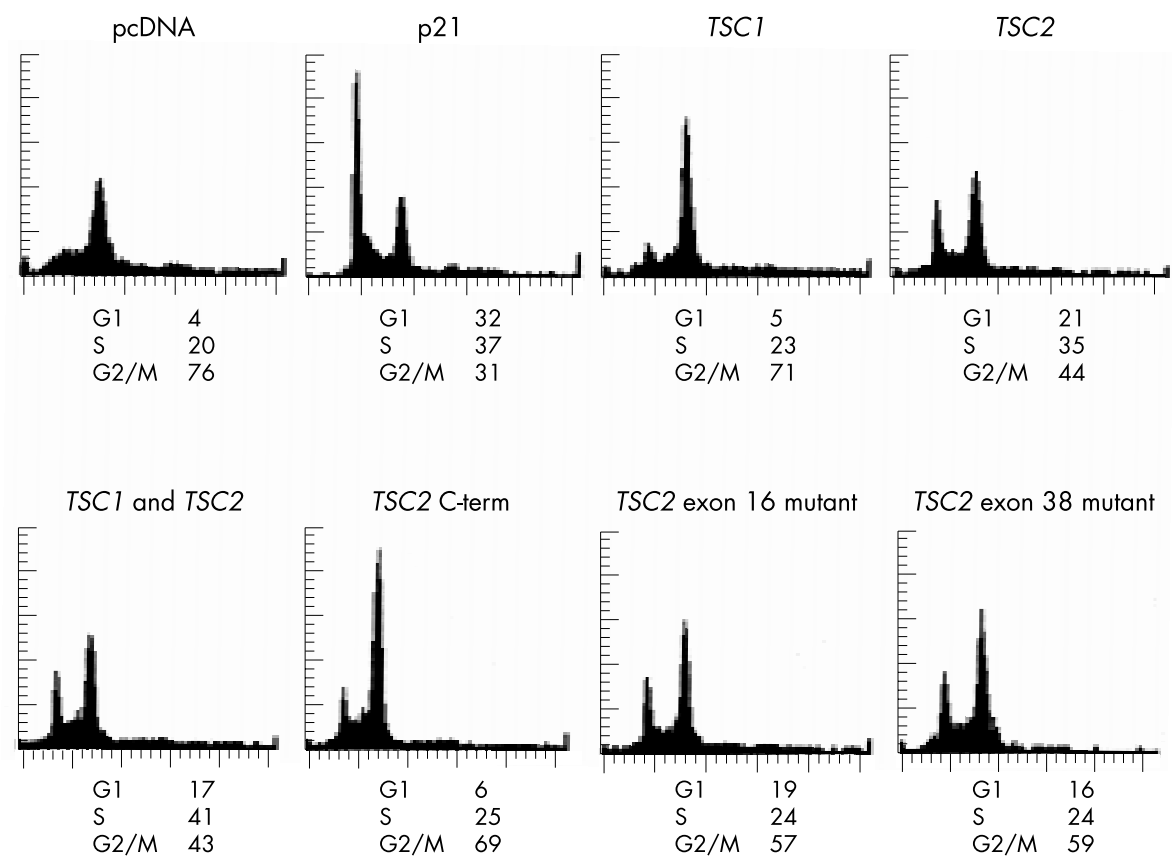

Figure 4 Representative fluorescence activated cell sorting analyses of cells cotransfected with CD19 and TSC1 or TSC2 and treated with nocodazole. Examples of cell cycle profiles are shown for each of the transfections in the presence of nocodazole. Each panel represents cells cotransfected with the indicated construct and CD19, and sorted for CD19 positivity. The percentage of cells in each phase of the cell cycle, as determined by ModFit analysis, is shown below the appropriate panel.

TSC2 exon 16 mutation, and $13.6 \%$ for the TSC2 exon 38 mutation $(\mathrm{p}<0.05$ for each construct compared with the vector control). These results support recent work in which three mutations within the GAP domain (N1643K, N1651S, and $\mathrm{N} 1681 \mathrm{~K}$ ) were found to have effects on the cell cycle that were similar to those of wild type TSC2, ${ }^{35}$ consistent with our results for the P1675L GAP domain mutant. Because these mutations occurred in patients with TSC, these data suggest that cell cycle regulation is not the primary mechanism through which tuberin functions as a tumour suppressor gene.

In addition to cell cycle regulation, mammalian tuberin and/or hamartin appear to be involved in other cellular pathways that may contribute to tumorigenesis: Rapl activation, ${ }^{36}$ vesicular trafficking, ${ }^{37}$ transcriptional activation by steroid hormones, ${ }^{38}$ and focal adhesion formation. ${ }^{39}$ The in vivo significance of these pathways and their contribution to the abnormal cell proliferation and abnormal cell cycle kinetics in TSC are not yet known. Clearly, it will be important to test the function of naturally occurring TSC2 missense mutations in these pathways.

While the exon 16 and exon 38 TSC2 mutants resulted in an increase in cells in the Gl phase of the cell cycle, the carboxyterminus construct containing the wild type GAP domain did not. An identical carboxy-terminus construct has been shown previously to reduce the in vitro proliferation of two Eker rat derived cell lines at a level similar to that of full length TSC2, and suppressed the in vivo tumorigenicity of one of the cell lines (as did full length TSC2). ${ }^{28}$ Our data may indicate that the carboxy-terminus of TSC2 is not required for the cell cycle effects of TSC2 overexpression, but is involved in growth suppression through other cellular pathways.

Other groups have observed increases in p27(KIP1) protein levels when TSC1 or TSC2 is overexpressed. ${ }^{15} 17$ We also found increases in p27(KIPl) levels when TSC1 or TSC2 was expressed (fig 2B), although only when the cells were exposed to nocodazole. The relative increase in p27(KIPl) compared with the control transfected cells, as determined by densitometry, was 3.3 for TSC1 transfection, 2.5 for TSC2 transfection, and 3.9 for the TSC2 exon 16 mutant transfection. An increase in p27(KIP1) was not seen when the TSC2 carboxy-terminus or the TSC2 exon 38 mutant construct was transfected. Similar results were seen in multiple independent transfections. Interestingly, in our study the p27(KIP1) increase was seen in TSCl transfected cells, despite the fact that TSCl did not affect the cell cycle profile. The exon 38 mutant (P1675L), which resulted in an increase in the Gl fraction, did not affect the p27(KIP1) level. In contrast, the exon 16 mutant (R61lQ) increased both G1 and p27(KIP1). These results functionally separate cell cycle regulation (predominantly mediated by tuberin and intact in the GAP domain mutant construct) from p27(KIP1) up regulation (mediated by tuberin and hamartin and lost in the GAP domain mutant construct).

In summary, we examined the cell cycle impact of transient expression of TSC1 and/or TSC2 using a two colour FACS assay. We found that expression of wild type TSC2, but not TSC1, increased the percentage of cells in the Gl phase of the cell cycle. No additive or synergistic effect occurred when TSCl and TSC2 were coexpressed. This is the first time that the cell cycle effects of TSC1 and TSC2 have been studied in parallel, and suggests that the cell cycle effects of the tuberin-hamartin complex derive primarily from tuberin, not hamartin. We also tested two naturally occurring mutant forms of TSC2, one within the region of GAP homology (P1675L) and one in exon 16 (R61lQ). We found that expression of either mutant also induced an increase in the Gl fraction, similar in magnitude to that of wild type TSC2. A similar result was recently reported for three other mutations in the GAP homology domain. ${ }^{35}$ There are several competing hypotheses that could explain the unexpected finding that expression of mutant forms of TSC2 increases the Gl fraction. First, it is possible that the domains affected by these mutations (including the GAP domain) are not involved in tuberin's cell cycle regulation. Second, overexpression of the mutant proteins could compensate for decreased activity in vivo at endogenous expression levels. Finally, it is possible that the Gl increase seen with expression of mutant TSC2 (as well as wild type) indicates that disruption of the cell cycle is not an important pathway of tumorigenesis in TSC, despite a number of studies indicating that wild type TSC2 and TSC1 regulate the G1 phase of the cell cycle. 


\section{ACKNOWLEDGEMENTS}

This work was supported by grants from the March of Dimes, the Tuberous Sclerosis Association (Silver Spring, Maryland), and the NIH (RO1 DK51052). Leena Khare was the recipient of a LAM Foundation (Cincinnati, OH) Research Fellowship. We are grateful to the Fox Chase Cancer Center Flow Cytometry Facility, to Dr Sam Litwin of the Fox Chase Cancer Center Biostatistics Facility for assistance with statistical analyses, and to Dr Maureen Murphy for critical review of the manuscript.

\section{Authors' affiliations}

L Khare, A Astrinidis, W Senapedis, P D Adams, E P Henske, Fox

Chase Cancer Center, Philadelphia, Pennsylvania, USA

Correspondence to: Dr E Petri Henske, Fox Chase Cancer Center, 7701 Burholme Avenue, Philadelphia, PA 19111, USA; EP Henske@fccc.edu

\section{REFERENCES}

1 Gomez M, Sampson JR, Whittemore VH, eds. Tuberous sclerosis complex. 3rd ed. New York: Oxford University Press, 1999.

2 European Chromosome 16 Tuberous Sclerosis Consortium. dentification and characterization of the tuberous sclerosis gene on chromosome 16. Cell 1993:75:1305-15.

3 van Slegtenhorst $M$, de Hoogt $R$, Hermans $C$, Nellist $M$, Janssen $B$ Verhoef S, Lindhout D, van den Ouweland A, Halley D, Young J, Burley M, Jeremiah S, Woodward K, Nahmias J, Fox M, Ekong R, Osborne J, Wolfe J, Povey S, Snell R, Cheadle J, Jones A, Tachataki M, Ravine D, Sampson J, Reeve M, Richardson P, Wilmer R, Munro C, Hawkins T, Sepp T, Ali J, Ward S, Green A, Yates J, Kwiatkowska J, Henske E, Short $M$, Haines J, Jozwiak S, Kwiatkowski D. Identification of the tuberous sclerosis gene TSC1 on chromosome 9q34. Science 1997;277:805-8.

4 van Slegtenhorst $M$, Nellist $M$, Nagelkerken $B$, Cheadle J, Snell $R$, van den Ouweland A, Reuser A, Sampson J, Halley D, van der Sluiis P. Interaction between hamartin and tuberin, the TSC 1 and TSC2 gene products. Hum Mol Genet 1998;7:1053-7.

5 Plank TL, Yeung RS, Henske EP. Hamartin, the product of the tuberous sclerosis 1 (TSC1) gene, interacts with tuberin and appears to be localized to cytoplasmic vesicles. Cancer Res 1998;58:4766-70.

6 Gao X, Pan D. TSC1 and TSC2 tumor suppressors antagonize insulin signaling in cell growth. Genes Dev 2001;15:1383-92.

7 Potter CJ, Huang H, Xu T. Drosophila Tsc1 functions with Tsc2 to antagonize insulin signaling in regulating cell growth, cell proliferation, and organ size. Cell 2001;105:357-68

8 Tapon N, Ito N, Dickson BJ, Treisman JE, Hariharan IK. The Drosophila tuberous sclerosis complex gene homologs restrict cell growth and cell proliferation. Cell 2001; 105:345-55

9 Ito N, Rubin GM. gigas, a Drosophila homolog of tuberous sclerosis gene product-2, regulates the cell cycle. Cell 1999:96:529-39.

10 Yeung RS, Xiao GH, Jin F, Lee WC, Testa JR, Knudson AG. Predisposition to renal carcinoma in the Eker rat is determined by germ-line mutation of the tuberous sclerosis 2 (TSC2) gene. Proc Natl Acad Sci USA 1994;91:11413-16.

11 Kobayashi R, Hirayama Y, Kobayashi E, Kubo Y, Hino O. A germline insertion in the tuberous sclerosis (Tsc2) gene gives rise to the Eker rat model of dominantly inherited cancer. Nat Genet 1995;9:70-4.

12 Kobayashi T, Minowa O, Sugitani Y, Takai S, Mitani H, Kobayashi E, Noda T, Hino O. A germ-line Tscl mutation causes tumor development and embryonic lethality that are similar, but not identical to, those caused by Tsc2 mutation in mice. Proc Natl Acad Sci USA 2001 ; 98:8762-7.

13 Kobayashi T, Minowa O, Kuno J, Mitani H, Hino O, Noda T. Renal carcinogenesis, hepatic hemangiomatosis, and embryonic lethality caused by a germ-line Tsc2 mutation in mice. Cancer Res 1999.59:1206-11

14 Onda H, Lueck A, Marks PW, Warren HB, Kwiatkowski DJ. Tsc2(+/-) mice develop tumors in multiple sites that express gelsolin and are influenced by genetic background. J Clin Invest 1999;104:687-95.

15 Miloloza A, Rosner M, Nellist M, Halley D, Bernaschek G, Hengstschlager $M$. The TSCl gene product, hamartin, negatively regulates cell proliferation. Hum Mol Genet 2000;9:172 1-7.

16 Soucek T, Pusch O, Wienecke R, DeClue JE, Hengstschlager M. Role of the tuberous sclerosis gene-2 product in cell cycle control. Loss of the tuberous sclerosis gene- 2 induces quiescent cells to enter $\mathrm{S}$ phase. J Biol Chem 1997;272:29301-8.
17 Soucek T, Yeung RS, Hengstschlager M. Inactivation of the cyclin-dependent kinase inhibitor p27 upon loss of the tuberous sclerosis complex gene-2. Proc Natl Acad Sci USA 1998;95:15653-8.

18 Zhu L, Enders G, Lees JA, Beijersbergen RL, Bernards R, Harlow E. The pRB-related protein p107 contains two growth suppression domains: independent interactions with $\mathrm{E} 2 \mathrm{~F}$ and cyclin/cdk complexes. EMBO J 1995:14:1904-13.

19 Zhu L, van den Heuvel S, Helin K, Fattaey A, Ewen M, Livingston D, Dyson N, Harlow E. Inhibition of cell proliferation by $\mathrm{p} 107$, a relative of the retinoblastoma protein. Genes Dev 1993;7:1111-25.

20 Nakamura N, Ramaswamy S, Vazquez F, Signoretti S, Loda M, Sellers WR. Forkhead transcription factors are critical effectors of cell death and cell cycle arrest downstream of PTEN. Mol Cell Biol 2000;20:8969-82.

21 van den Heuvel S, Harlow E. Distinct roles for cyclin-dependent kinases in cell cycle control. Science 1993;262:2050-4.

22 Koh J, Enders GH, Dynlacht BD, Harlow E. Tumour-derived p16 alleles encoding proteins defective in cell-cycle inhibition. Nature 1995;375:506-10

23 Craig C, Kim M, Ohri E, Wersto R, Katayose D, Li Z, Choi YH, Mudaha B, Srivastava S, Seth P, Cowan K. Effects of adenovirus-mediated pl6INK4A expression on cell cycle arrest are determined by endogenous $\mathrm{p} 16$ and $\mathrm{Rb}$ status in human cancer cells. Oncogene $1998 ; 16: 265-72$

24 Hall C, Nelson DM, Ye X, Baker K, DeCaprio JA, Seeholzer S, Lipinski $M$, Adams PD. HIRA, the human homologue of yeast Hirlp and Hir2p, is a novel cyclin-cdk2 substrate whose expression blocks S-phase progression. Mol Cell Biol 2001;21:1854-65.

25 Vairo G, Livingston DM, Ginsberg D. Functional interaction between E2F-4 and p130: evidence for distinct mechanisms underlying growth suppression by different retinoblastoma protein family members. Genes Dev 1995; 9:869-81.

26 Qin XQ, Livingston DM, Ewen M, Sellers WR, Arany Z, Kaelin WG Jr. The transcription factor E2F-1 is a downstream target of RB action. Mol Cell Biol 1995; 15:742-55.

27 Adams PD, Lopez P, Sellers WR, Kaelin WG Jr. Fluorescence-activated cell sorting of transfected cells. Methods Enzymol 1997;283:59-72.

28 Jin F, Wienecke R, Ziao G, Maize J, DeClue J, Yeung R. Suppression of tumorigenicity by the wild-type tuberous sclerosis 2 (TSC2) gene and its C-terminal region. Proc Natl Acad Sci USA 1996;93:9154-9.

29 Dabora SL, Jozwiak S, Franz DN, Roberts PS, Nieto A, Chung J, Choy YS, Reeve MP, Thiele E, Egelhoff JC, Kasprzyk-Obara J, Domanska-Pakiela D, Kwiatkowski DJ. Mutational analysis in a cohort of 224 tuberous sclerosis patients indicates increased severity of TSC2, compared with TSC1, disease in multiple organs. Am J Hum Genet $2001 ; 68: 64-80$

30 Carsillo T, Astrinidis A, Henske EP. Mutations in the tuberous sclerosis complex gene TSC2 are a cause of sporadic pulmonary lymphangioleiomyomatosis. Proc Natl Acad Sci USA 2000:97:6085-90.

31 Biornsson J, Henske E, Bernstein J. Renal Manifestations. In: Gomez M Sampson J, Whittemore V, eds. Tuberous sclerosis complex. 3rd ed. Oxford: Oxford University Press, 1999:181-93.

32 Shepherd CW, Gomez MR, Lie JT, Crowson CS. Causes of death in patients with tuberous sclerosis. Mayo Clin Proc 1991;66:792-6.

33 Stewart ZA, Tang L, Pietenpol JA. Increased p53 phosphorylation after microtubule disruption is mediated in a microtubule inhibitor- and cell-specific manner. Oncogene 2001;20:113-24.

34 Jones AC, Shyamsundar MM, Thomas MW, Maynard J, Idziaszczyk S, Tomkins S, Sampson JR, Cheadle JP. Comprehensive mutation analysis of TSC1 and TSC2 - and phenotypic correlations in 150 families with tuberous sclerosis. Am J Hum Genet 1999;64:1305-15.

35 Soucek T, Rosner M, Miloloza A, Kubista M, Cheadle JP, Sampson JR, Hengstschlager $M$. Tuberous sclerosis causing mutants of the TSC2 gene product affect proliferation and p27 expression. Oncogene 2001;20:4904-9

36 Wienecke R, Konig A, DeClue JE. Identification of tuberin, the tuberous sclerosis-2 product. Tuberin possesses specific Rap IGAP activity. J Biol Chem 1995:270:16409-14.

37 Xiao GH, Shoarinejad F, Jin F, Golemis EA, Yeung RS. The tuberous sclerosis 2 gene product, tuberin, functions as a Rab5 GTPase activating protein (GAP) in modulating endocytosis. J Biol Chem 1997;272:6097-100

38 Henry KW, Yuan X, Koszewski NJ, Onda H, Kwiatkowski DJ, Noonan DJ. Tuberous sclerosis gene 2 product modulates transcription mediated by steroid hormone receptor family members. J Biol Chem 1998;273:20535-9

39 Lamb RF, Roy C, Diefenbach TJ, Vinters HV, Johnson MW, Jay DG, Hall A. The TSCl tumour suppressor hamartin regulates cell adhesion through ERM proteins and the GTPase Rho. Nat Cell Biol 2000;2:281-7. 